\title{
Posterior cortical dementia with alexia: neurobehavioural, MRI, and PET findings
}

\author{
L Freedman, D H Selchen, S E Black, R Kaplan, E S Garnett, C Nahmias
}

\begin{abstract}
A progressive disorder of relatively focal but asymmetric biposterior dysfunction is described in a 54 year old right handed male. Initial clinical features included letter-by-letter alexia, visual anomia, acalculia, mild agraphia, constructional apraxia, and visuospatial compromise. Serial testing demonstrated relentless deterioration with additional development of transcortical sensory aphasia, Gerstmann's tetrad, and severe visuoperceptual impairment. Amnesia was not an early clinical feature. Judgment, personality, insight, and awareness remained preserved throughout most of the clinical course. Extinction in the right visual field to bilateral stimulation was the sole neurological abnormality. Early CT was normal and late MRI showed asymmetrical bioccipitoparietal atrophy with greater involvement of the left hemisphere. Results from positron emission tomography (PET) showed bilaterally asymmetric (left > right) occipitotemporoparietal hypometabolism. The metabolic decrement was strikingly asymmetric with a $50 \%$ reduction in glucose consumption confined to the left occipital cortex. The picture of occipitotemporoparietal compromise verified by MRI, PET, and neurobehavioural testing would be unusual for such degenerative dementias as Alzheimer's (AD) and Pick's disease, although atypical AD with predominant occipital lobe involvement cannot be excluded. This case supports the concepts of posterior cortical dementia (PCD) as a clinically distinct entity and for the first time documents its corresponding metabolic deficit using PET.
\end{abstract}

Focal and diffuse cortical syndromes distinct from Alzheimer's and Pick's disease are becoming increasingly recognised..$^{1-8}$ Included among these are the syndromes of progressive aphasia without dementia, ${ }^{125}$ progressive apraxia ${ }^{3}$ frontal lobe dementia, ${ }^{67}$ argyrophilic grain disease, ${ }^{8}$ and a posterior dementia. ${ }^{34}$ While some scepticism still remains that some of these syndromes represent atypical variants of Alzheimer's (AD) or Pick's disease, ${ }^{911}$ evidence derived from metabolic, ${ }^{12}$ regional blood flow, ${ }^{13}$ and neuropathological ${ }^{568}$ investigations have clearly supported their status as distinct neurological entities.
The syndrome of posterior cortical dementia (PCD) described by Benson et al $^{14}$ and De Renzi ${ }^{3}$ is clinically dominated by disturbances in visual function including object agnosia, prosopagnosia, alexia, and visuospatial disorientation. The development of transcortical sensory aphasia and a complete Gerstmann's and Balint's syndrome was also present in several patients. Computed tomography ${ }^{34}$ and $\mathrm{MRI}^{4}$ in PCD revealed prominent posterior atrophy characterised by enlargement of the occipital horns. However, the topography of cerebral metabolic dysfunction using positron emission tomography (PET) has yet to be described for PCD.

We examined a patient with serial neurobehavioural testing complimented by MRI and PET who exhibited PCD. The dementia was notable for the presence of a severe letter-byletter alexia and profound bioccipital (left > right) hypometabolism verified by PET.

\section{Case report}

A 54 year old, right handed man with two doctoral degrees was referred for neurological examination in February 1986 after complaining to his family physician of progressive difficulty in reading, mathematical ability, and memory function over the previous three years. These problems were at first mild, but became disturbing given his aptitude in mechanical engineering and economics. He was aware of the impairments and was able to manage a private business despite his reduced cognitive capabilities.

A neurological examination performed in February 1986 revealed an alert and oriented man with intact cranial nerves. There were no orbital, cranial, or carotid bruits and visual fields were full to confrontation. Sensorimotor function, gait, and coordination were intact and primitive reflexes were absent. Examination of the skull, chest, and heart was negative. Haematological studies revealed a normal CBC, electrolytes, enzymes; thyroid, B12, folate levels, VDRL, ESR, and ANF counts. Analysis of the CSF was normal. An EEG showed non-specific slowing in the temporal lobes, bilaterally, and CT revealed no focal lesions or significant atrophy. Medical history was negative for cerebrovascular and cardiovascular disease, subarachnoid haemorrhage, intracranial infection, cerebral tumour, hypertension, diabetes, and psychiatric illness. Family history was negative for dementia.

Serial neurobehavioural examinations were conducted over a three year period beginning 
Table 1 Language and reading data: serial findings

\begin{tabular}{|c|c|c|c|c|}
\hline Measure & $\begin{array}{l}\text { February } \\
86\end{array}$ & $\begin{array}{l}\text { December } \\
86\end{array}$ & $\begin{array}{l}\text { April } \\
88\end{array}$ & $\begin{array}{l}\text { October } \\
88\end{array}$ \\
\hline WRAT reading & 39 th $\%$ & 37 th $\%$ & - & - \\
\hline PIAT reading recognition & - & $3 \mathrm{rd} \%$ & $<1 \mathrm{st} \%$ & - \\
\hline PIAT reading comprehension & - & $1 \mathrm{st} \%$ & $<1 \mathrm{st} \%$ & - \\
\hline Boston Naming Test $(60$-items) & - & 33 & 22 & 19 \\
\hline Tactile Naming Test* & - & - & - & $5 / 16$ \\
\hline Token Test (36-items) & - & 22 & 9 & 1 \\
\hline Word discrimination (BDAE) & - & $60 / 72$ & $52 / 72$ & - \\
\hline Written naming (BDAE) & $8 / 10$ & $6 / 10$ & $4 / 10$ & - \\
\hline Word-picture matching (BDAE) & - & $8 / 10$ & $0 / 10$ & - \\
\hline Writing-to-Dictation & $15 / 19$ & $13 / 19$ & $3 / 10$ & - \\
\hline Word repetition (BDAE) & - & $90 \%$ & - & $100 \%$ \\
\hline High-phrase repetition (BDAE) & - & $100 \%$ & - & $40 \%$ \\
\hline Low-phrase repetition (BDAE) & - & $75 \%$ & - & $25 \%$ \\
\hline
\end{tabular}

WRAT $=$ Wide range achievement test. PIAT $=$ Peabody individual achievement test. BDAE = Boston diagnostic aphasia examination. WRAT and PIAT scores in percentiles. ${ }^{\star}$ Naming of 16 common objects using the right hand.

in February 1986. Initial testing of language function (table 1) showed a mild anomia and agraphia. He also exhibited a severe alexic disturbance. Latency and accuracy in oral reading of single words ${ }^{14}$ as a function of word-length revealed a positive linear relationship consistent with a letter-by-letter or pure alexia (fig 1a-b). Further analysis of his oral reading ability revealed a reading rate of approximately one second per letter which is in keeping with the word-length effect of previously described letter-by-letter readers who had focal left occipitotemporal lesions. ${ }^{15-18}$ Visual paralexias were common ${ }^{17}$ and he committed right-sided derivational reading errors ${ }^{19}$ as well. Both oral reading and comprehension $^{20}$ of letters and words eventually became impossible. The early anomia progressed into a severe transcortical sensory aphasia with considerably compromised naming $^{21}$ and auditory comprehension. ${ }^{22}$ Single word repetition remained intact. Tactile naming was also severely defective although he was able to correctly pantomime the function of objects he failed to name.

Results of the general neurobehavioural assessment (table 2) revealed moderate compromise in overall $\mathrm{IQ}^{23}$ characterised by a large discrepancy between average verbal and his severely impaired visuospatial abilities. $\mathrm{He}$ exhibited a profound constructive apraxia and acalculia and subsequent examination revealed significant interval declines in both the verbal and spatial domains. Further IQ testing was precluded because of his severe aphasia and visuoperceptual compromise, but low-level cognitive screening ${ }^{24}$ conducted two years after the initial examination showed severe impairments in attention, calculation, and constructional skills. Memory ability was moderately impaired initially for both verbal and nonverbal material ${ }^{25}$ and later became untestable due to severe aphasia. Despite his impaired psychometric memory, he was not amnestic in his everyday functioning until very late in the clinical course. Visuospatial reasoning, ${ }^{26}$ hemispatial search, ${ }^{27}$ and copying ability $^{28}$ (Fig 2a-c) were also severely compromised. In addition, evidence of right hemispatial neglect was seen on visuoconstructive copy of relatively simple stimuli. ${ }^{25}$

The patient eventually developed a com- plete Gerstmann's syndrome (acalculia, agraphia, finger agnosia, right-left disorientation) and ocular dysmetria, which is one component of Balint's syndrome. Despite evolving visuoperceptual compromise, he was able to recognise inanimate objects but had difficulty identifying animals. He was, however able to point to photographs of inanimate and animate objects named aloud by the examiner without error using a multiple-choice format. The matching of black and white photographs of unfamiliar faces ${ }^{29}$ was relatively intact $(80 \%)$ and he was able to recognise $14 / 19$ (73\%) photographs of famous faces using a multiple choice format. He never failed to recognise the examiner (LF) over the serial examinations. He was totally unable to locate any continents, oceans, or countries on a large world map and did not exhibit any environmental agnosia ${ }^{30}$ until late in the course. He did not exhibit any colour agnosia, achromatopsia, or ideomotor apraxia. Personality, insight, judgment, comportment, and awareness remained intact throughout most of the clinical course until the development of paranoid ideation three years after the initial neurological evaluation.

Repeat neurological testing performed five, 27 , and 39 months after the initial examination revealed normal cranial nerves, sensorimotor function, reflexes, and gait. However, visual confrontation testing revealed persistent right visual field extinction. MRI scanning performed in September 1988 showed bilateral occipitoparietal atrophy
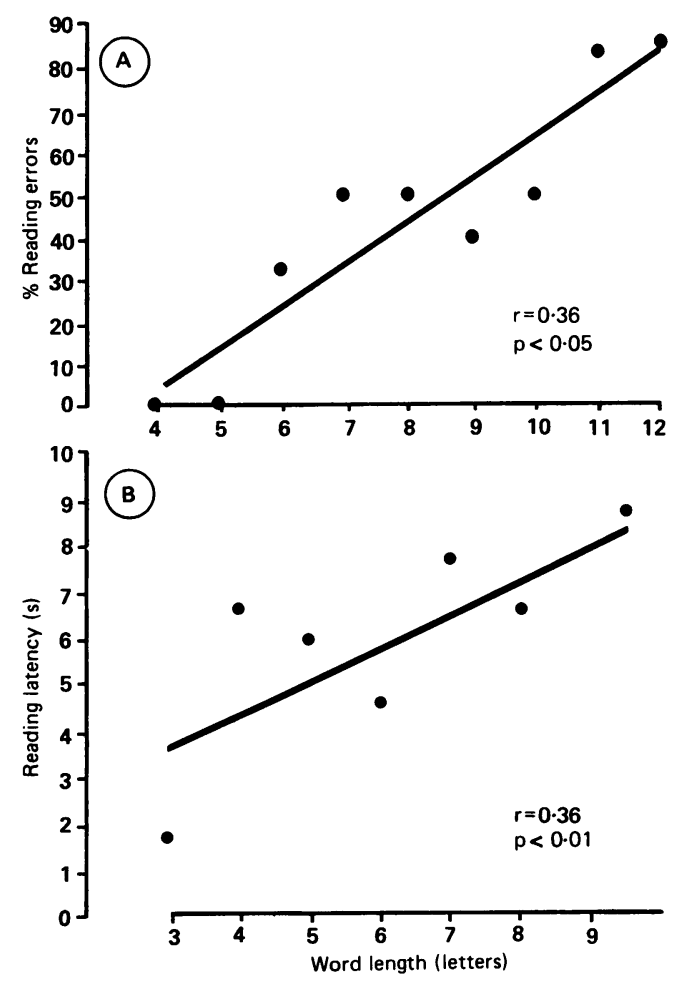

Figure 1 Oral reading performance at second examination, December 1986. A) Reading accuracy as a function of word length on the reading subtest of the Wide Range Achievement Test. B) Scattergram showing relationship between reading latency of 35 words $(7$ sets $\times 5$ words) as a function of word length. Regression equation for latency data is $Y=1 \cdot 3+0.79 X$. 
Table 2 Neurobehavioural data: serial findings

\begin{tabular}{llll}
\hline Measure & $\begin{array}{l}\text { February } \\
86\end{array}$ & $\begin{array}{l}\text { December } \\
86\end{array}$ & $\begin{array}{l}\text { Age-normal } \\
\text { values }\end{array}$ \\
\hline WAIS-R FSIQ & 83 & 73 & $100( \pm 15)$ \\
WAIS-R VIQ & 94 & 85 & $100( \pm 15)$ \\
WAIS-R PIQ & 68 & 59 & $100( \pm 15)$ \\
WMS MQ & 79 & 75 & $100( \pm 15)$ \\
RAVLT (Total 1-5) & $16 / 75$ & $10 / 75$ & $52 / 75( \pm 2)$ \\
RAVLT Recognition & $90 \%$ & $66 \%$ & $96 \%( \pm 1)$ \\
Raven's Matrices & $18 / 36$ & $11 / 36$ & $31 / 36( \pm 4)$ \\
Visual Search Right & 17 & 14 & $4.6( \pm 1)$ \\
Visual Search Left & 5 & 14.5 & $3.9( \pm 1)$ \\
WRAT arithmetic & 19 th\% & 10 th $\%$ & - \\
\hline
\end{tabular}

*Score reflects median hemispatial search time in seconds.

WAIS-R = Wechsler adult intelligence scale-revised.

RAVLT $=$ Rey auditory-verbal learning test ( 5 trials).

WMS MQ = Wechsler memory scale memory quotient.

Standard deviation in parentheses.

which was more prominent in the left hemisphere (fig $3 a-c)$. The sulcal enlargement extended into the left temporal region and there was asymmetric dilatation of the occipital horns which was greater on the left.

\section{PET methods and findings}

The patient had glucose metabolic scanning of the brain in May 1988. Cerebral glucose utilisation was measured using the McMaster positron emission tomograph which has a spatial resolution of $8 \mathrm{~mm}$ (full width at half maximum) in the plane and $12 \mathrm{~mm}$ in the axial direction. Additional technical details and performance characteristics of the tomograph are described elsewhere. ${ }^{31}$

For this study, the patient was administered $2.0 \mathrm{mCi}$ of [18F]-2-Fluoro-2-deoxyglucose (18 FDG) intravenously while lying on a comfortable stretcher. He was instructed to keep his eyes closed and background ambient noise was kept to a minimum. The patient's head was held in a perspex restraining device so that it could be positioned reproducibly within the tomograph. Alignment in the left to right axis was assured by inspection of a preliminary scan taken at the level of the thalamus. Scanning was started one hour after administration of the [18F] FDG. Twenty three sequential scans were taken at three minute intervals in a plane parallel to the orbitomeatal line. Each PET slice was $15 \mathrm{~mm}$ thick and overlapped its predecessor by $10 \mathrm{~mm}$. By adopting this procedure, the slice with the greatest volume of grey matter of interest could be identified and selected. The twenty three scans were interpreted by one of the authors (ESG) by comparing the pattern of global and regional distribution of glucose utilisation to a data base of normal control values.

\section{Results}

The patient's PET scan demonstrated bilateral asymmetric occipitotemporoparietal hypometabolism (fig 4a-d). Based on right/left comparisons of homologous brain regions, there was a $50 \%$ reduction in glucose metabolism in the left occipital lobe (fig 4a-b). A lesser, yet still marked degree of hypometabolism was revealed bilaterally in the medial occipital and temporal regions, including the hippocampus (fig 4a). Glucose consumption was also reduced in the temporoparietal and parieto-occipital regions, bilaterally (fig $4 c-d$ ). The degree of hypometabolism was significantly greater in the left hemisphere in all PET images showing bilaterally reduced glucose consumption. Hypometabolism was also noted in the left thalamus (fig $4 a$ ) and there was a $10 \%$ generalised reduction in metabolism involving the entire left hemisphere.

\section{Discussion}

The emergent clinical picture presented by our patient best exemplified a PCD. The pattern of neurobehavioural impairments including letter-by-letter alexia, acalculia, agraphia, spatialperceptual compromise, constructive apraxia, transcortical sensory aphasia, Gerstmann's syndrome, ocular dysmetria, and right visual field extinction unequivocally conformed to a topography of posterior hemispheric involvement. This pattern was substantiated by the MRI findings of bilateral occipitoparietal atrophy and by the PET results of bilateral occipitotemporoparietal hypometabolism using 18-FDG.

The clinical, radiological, and neurobehavioural findings in our patient bear a striking
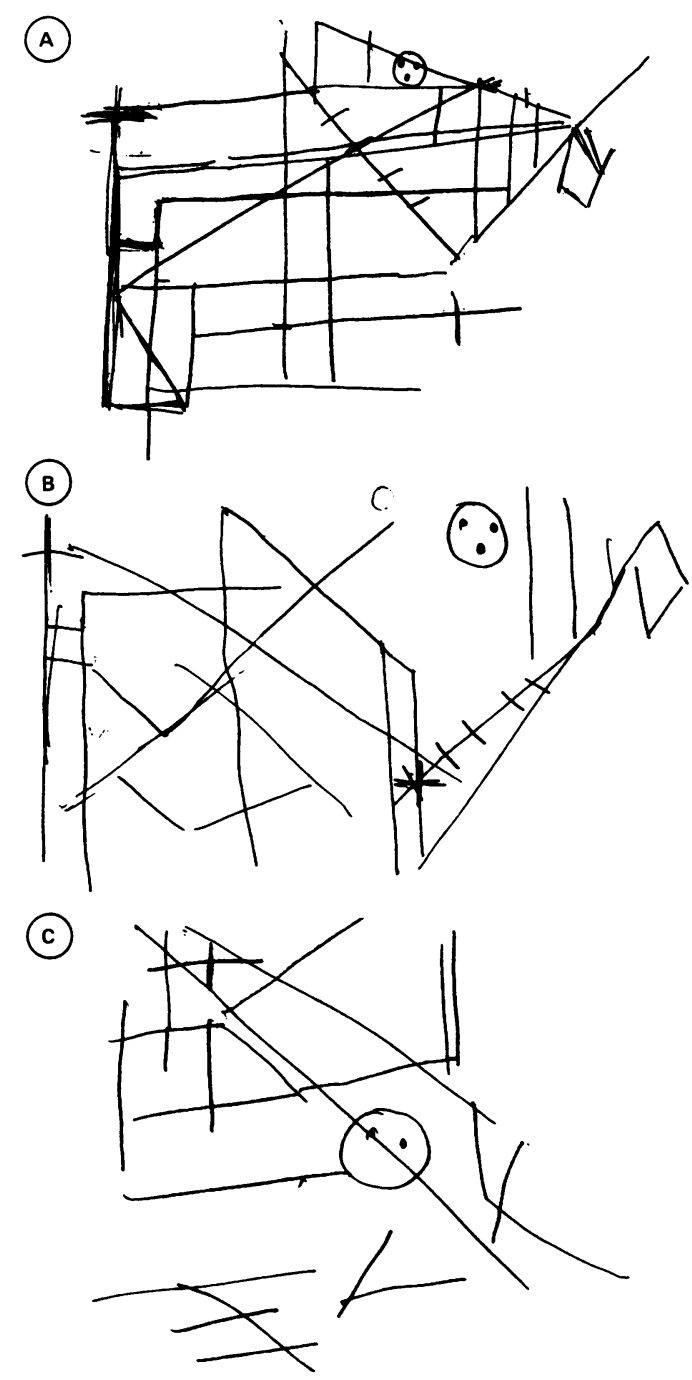

Figure 2A-C Copy of the Rey-Osterrieth Complex Figure. A) February 1986. B) December 1986. C) April 1988. Note the progressive impairment in spatial and visuoconstructive ability over time. 


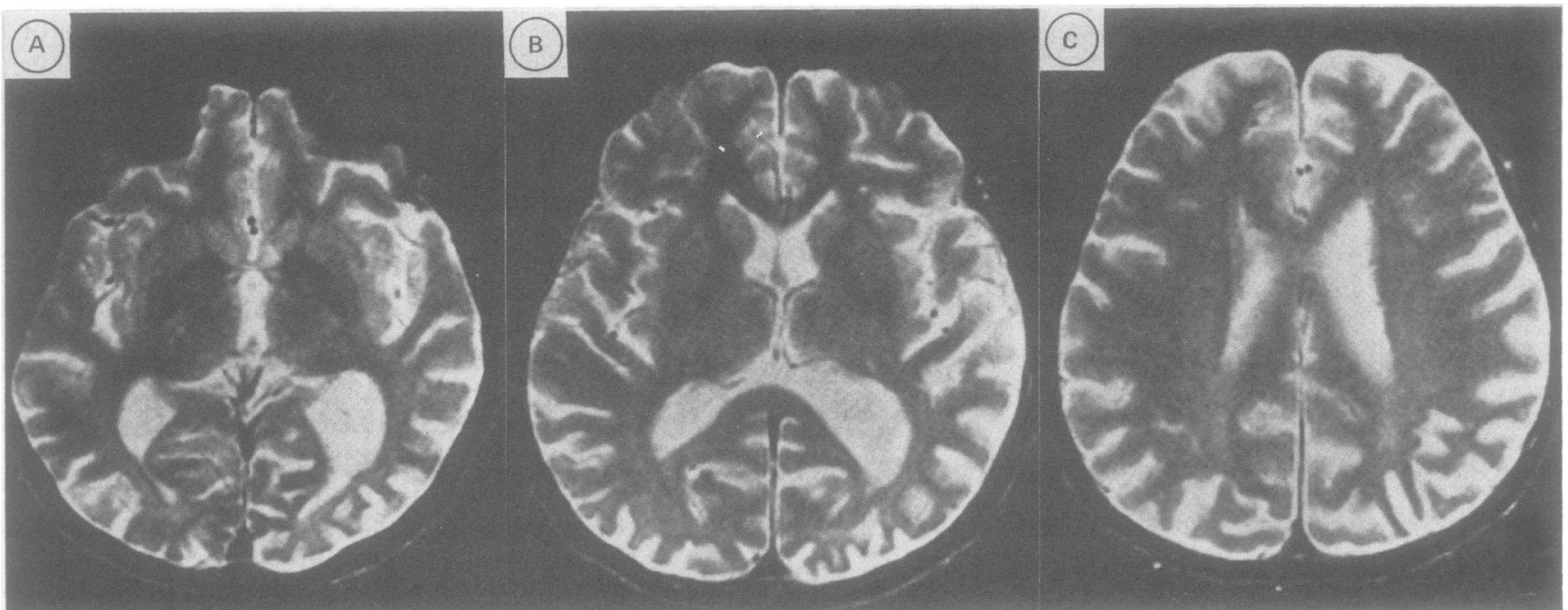

Figure 3A-C T-2 weighted MRI images in the axial plane (1.5 Tesla, TR $2000 \mathrm{~ms}$, TE $80 \mathrm{~ms}, 5 \mathrm{~mm}$ slice thickness, display matrix $256 \times 256$ ). The MRI images reveal marked bilateral occipitoparietal atrophy. The atrophy is asymmetrically more prominent in the left occipital region (right side of image) and extends into the ipsilateral posterior temporal area.

resemblance to three previously reported studies describing PCD. ${ }^{3432}$ The patients described in these reports presented with early deficits in complex visual processing including alexia, agnosia, spatial-perceptual compromise, Balint's syndrome, and environmental agnosia. Acalculia was also a common finding although Gerstmann's tetrad, transcortical sensory aphasia, and Balint's syndrome were
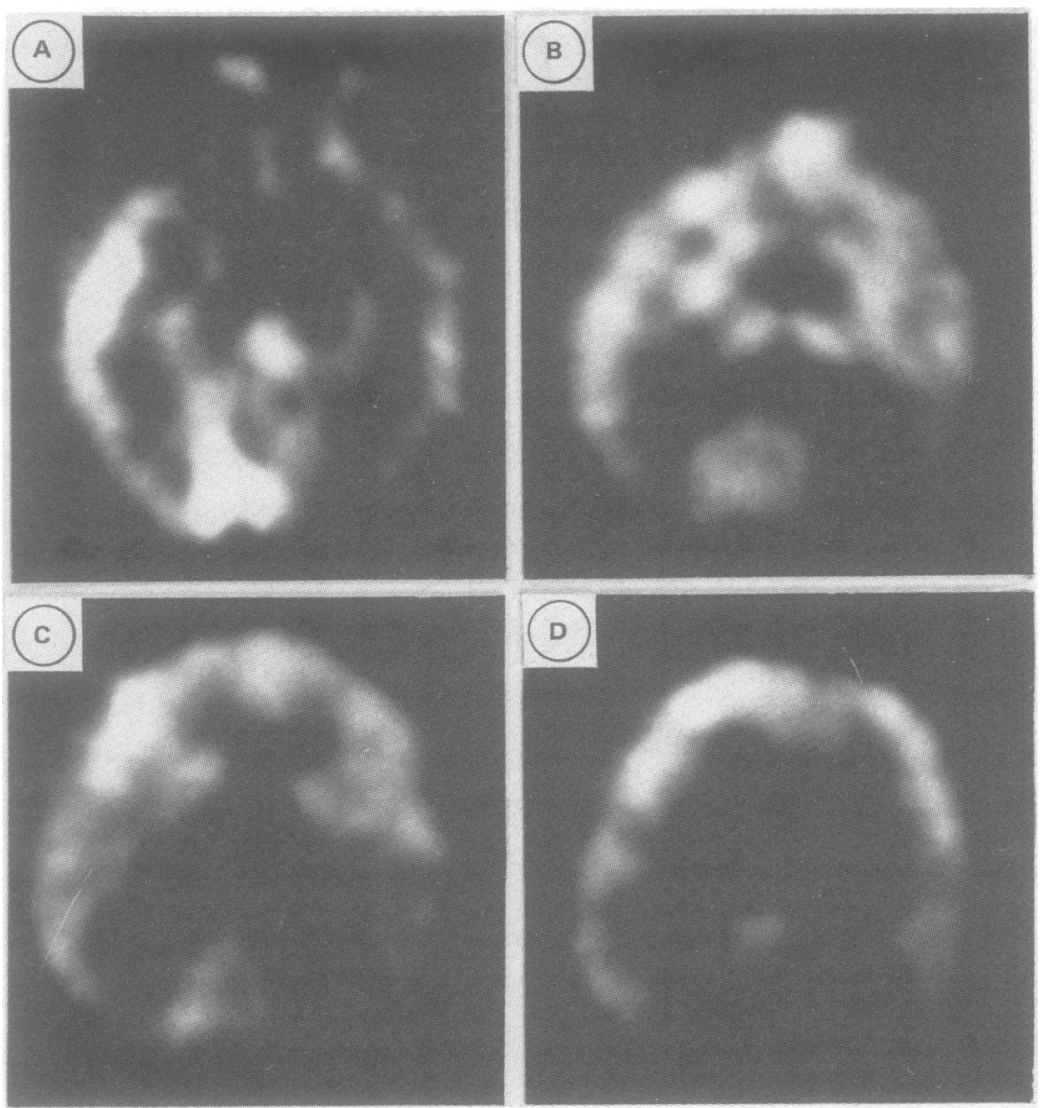

Figure 4A-D Positron emission tomographic sections at the level of the hippocampal gyri $A$ ), the thalamus $B$ ), the upper border of the caudate nuclei $C$ ), and the corpus callosum $D$ ). In each section, the patient's nose is towards the top of the picture and the left hemisphere is on the reader's right. Areas depicted in white represent regions of highest glucose consumption; those in black represent areas of lowest glucose consumption. The PET images reveal bilaterally asymmetric occipitotemporoparietal hypometabolism (left $>$ right) with prominent reduction in glucose consumption confined to the left occipital lobe. absent in some cases. ${ }^{32}$ The differences in clinical presentation and expression of cognitive deficits in our patient compared with others with PCD could be attributed to behavioural heterogeneity and variability in the rate of disease progression. CT in two cases ${ }^{3}$ and MRI in two others ${ }^{41}$ showed bilateral and symmetric occipitoparietal atrophy. Regional cerebral metabolic function, however, was not examined in any of these studies.

A salient finding of our case was the PET results of bilaterally asymmetric occipitotemporoparietal hypometabolism. To our knowledge, this is the first report describing the topography of metabolic impairment in PCD. The left hemisphere showed a greater degree of decreased metabolism than the right. This was most marked in the inferior and lateral occipital regions, the inferior, middle, and superior gyri of the posterior temporal lobes, and the inferior parietal regions encompassing the angular and supramarginal gyri. The presence of letter-byletter alexia, Gerstmann's syndrome, transcortical sensory aphasia, and right visual field extinction correlate well with the anatomic distribution of left posterior hypometabolism while the profound visuoperceptual and spatial impairment is likely to reflect the bilateral posterior deficits seen on PET.

The most striking deficit in our patient was his alexia. The alexic disturbance was characterised by a letter-by-letter decoding strategy ${ }^{18}$ and to our knowledge, this type of reading disorder has not been described in patients with progressive dementias. Cogan ${ }^{32}$ described three patients, one with demonstrated $\mathrm{AD}$ pathology (distribution unknown), who presented with progressive perceptual disturbances, including alexia without agraphia, although the qualitative features of the reading disorder were not described. Our patient showed a significant word-length effect ${ }^{15-18}$ and made visual paralexic ${ }^{16}$ and right-sided derivational errors ${ }^{19}$ on measures of oral reading. His alexia therefore resembled the type of reading disorder usually seen in patients having focal damage to the left occipitotemporal region $^{33}$ and the hypometabolism in this 
anatomic area can be presumed to underlie the alexia.

Alexia can be an early manifestation of $\mathrm{PCD}^{4}$ although the nature of the reading disorder has not been well delineated. The alexic disturbance in PCD serves to distinguish it from other progressive cortical syndromes. Oral reading ability is usually spared until the later stages in AD..$^{34}{ }^{35}$ Oral reading ability in Pick's disease and progressive aphasia without dementia has received little attention, and any reading disturbance would most likely be secondary to the prominence of aphasia in these disorders. ${ }^{134}$ Goulding et $a^{\beta^{6}}$. recently reported the absence of any oral reading disturbance in a case of progressive aphasia without dementia accompanied by right-sided extrapyramidal symptoms. The description of oral reading performance in patients with frontal lobe dementia and grain argyrophilic disease has yet to be reported, although a letter-by-letter alexia would not likely be present given the absence of significant occipital lobe pathology in these disorders. ${ }^{68}$

The pattern of metabolic dysfunction in PCD differs significantly from that described in other progressive cortical syndromes. PET findings in $\mathrm{AD}$ have consistently demonstrated bilateral temporoparietal/frontal hypometabolism, ${ }^{37-42}$ which is occasionally asymmetric depending on whether language or visuospatial disturbances predominate along with global memory dysfunction. ${ }^{37-41}$ The metabolic picture in Pick's disease, which is characterised by frontotemporal atrophy, is less studied, but a recent report revealed a marked frontal lobe hypometabolic defect. ${ }^{43}$ In several cases of progressive aphasia without dementia, PET results have shown left temporoparietal hypometabolism. ${ }^{12}$ Studies of regional blood flow in frontal lobe dementia have revealed reduced perfusion confined to the prefrontal regions while the metabolic picture in argyrophilic grain disease has yet to be described. The occipitotemporoparietal hypometabolism seen in PCD, with its prominent occipital lobe focus, is quite distinct in its topographic distribution compared with the progressive syndromes mentioned above.

The neuropathology underlying PCD is unknown. The finding of occipitoparietal atrophy on MRI in this and one other report ${ }^{4}$ raises the possibility that $\mathrm{PCD}$ reflects a posterior variant of a focal lobar degeneration similar to Pick's disease or frontal lobe dementia. Atypical AD with predominant occipital symptomatology ${ }^{32}$ and pathology ${ }^{44}$ cannot be excluded from the differential diagnosis, although this would be a distinctly unusual presentation. Consideration of a vascular aetiology is also warranted given evidence that a strategically-placed lesion can produce symptoms similar to PCD ${ }^{45}$ However, no evidence of focal infarction was seen on CT or MRI, and the non-stepwise, neurobehavioural decline in PCD argues against a vascular aetiology.

Recently, Kirshner et al ${ }^{5}$ presented neuropathological evidence in two cases of progressive aphasia without dementia. They described focal spongiform changes and mild astrocytosis involving layer two of the left inferior frontal gyrus. No pathological changes resembling $\mathrm{AD}$, Pick's disease, or CreutzfeldtJakob disease (CJD) were observed. In another recent report, Mandell et $a l^{46}$ described a patient with necropsy findings of CreutzfeldtJakob disease who initially presented with an isolated progressive aphasia who suffered generalised cognitive decline one year after onset of the language disturbance. The time course in our patient (seven years) and other cases of PCD would not support classic CJD as an underlying aetiology although several cases of atypical, long-duration CJD have been documented ${ }^{47}$. Thus the possibility exists that PCD may represent a posterior variant of a focal spongiform disorder or an atypical presentation of CJD.

In conclusion, our findings and previous reports, ${ }^{34}$ support the concept of $\mathrm{PCD}$ as a clinically distinct neurological entity. PCD is clinically, radiologically, metabolically, and neurobehaviourally distinct from other varieties of progressive cortical syndromes. Whether PCD represents a posterior variant of a focal spongiform disorder or an atypical expression of $\mathrm{AD}$, Pick's disease, CJD, or an as yet unrecognised entity ultimately awaits pathological verification.

We thank Dr Attila Gyorody for initially referring the patient. Portions of this paper were presented at the 17th annual meeting
of the International Neuropsychological Society, Vancouver, of the International Neuropsychological
British Columbia, Canada, February 1989.

1 Mesulam M-M. Slowly progressive aphasia without generalised dementia. Ann Neurol 1982;11:592-8.

2 Heath PD, Kennedy P, Kapur N. Slowly progressive aphasia without dementia. Ann Neurol 1983;13:687-8.

3 De Renzi E. Slowly progressive visual agnosia or apraxia without dementia. Cortex 1986;22:171-80.

4 Benson DF, Davis JR, Snyder BD. Posterior cortical atrophy. Arch Neurol 1988;45:789-93.

5 Kirshner HS, Tanridag O, Thurman L, Westsell WD. Progressive aphasia without dementia: Two cases with focal spongiform degeneration. Ann Neurol 1987;22: 527-32.

6 Brun A. Frontal lobe degeneration of non-Alzheimer type. I. Neuropathology. Arch Gerontol Geriatr 1987;6:193-208.

7 Neary D, Snowden JS, Northen B, Goulding P. Dementia of frontal lobe type. J Neurol Neurosurg Psychiatry 1988;51:353-61.

8 Itagaki S, McGeer PL, Akiyama $\mathrm{H}$, et al. A case of adultonset dementia with argyrophilic grains. Ann Neurol 1989;26:685-9.

9 Foster NL, Chase TN. Diffuse involvement in progressive aphasia. Ann Neurol 1983;13:224-5.

10 Gordon B, Selnes O. Progressive aphasia "without aphasia". evidence of more widespread involvement. Neurology 1984;34:102.

11 Poeck K, Luzzatti C. Slowly progressive aphasia in three patients. The problem of accompanying neuropsy-

12 Chawluk JB, Mesulam M-M, Hurtig H, et al. Slowly progressive aphasia without generalized dementia. Srogressive aphasia without generalized dementia. 1986;19:68-74.

13 Risberg J. Frontal lobe degeneration of non-Alzheimer type. III. Regional cerebral blood flow. Arch Gerontol Geriatr 1987;6:225-33.

14 Jastak JF, Jastak SR. The Wide Range Achievement Test. Wilmington, Delaware: Guidance Associates, 1965.

15 Warrington EK, Shallice T. Word-form dyslexia. Brain 1980;103:99-112.

16 Bub D, Black SE, Howell J. Word recognition and context effects in a letter-by-letter reader. Brain Lang (in press).

17 Henderson VW, Friedman RB, Teng EL, Weiner JM. Left hemisphere pathways in reading: Inferences from pure alexia without hemianopia. Neurology 1985;35:962-8.

18 Patterson K, Kay J. Letter-by-letter reading. Psychological descriptions of a neurological syndrome. Q J Exp Psychol [A] 1982;34A:411-41.

19 Patterson KE. Derivational errors. In: Coltheart K, Patterson KE, Marshall JC, eds. Deep dyslexia. London: Routledge and Keegan Paul, 1980:286-306.

20 Dunn LM, Markwardt FC. Peabody Individual Achievement Test. Circle Pines: American Guidance, 1970. 
21 Kaplan E, Goodglass H, Weintraub S. Boston Naming Test. Philadelphia: Lea and Fibiger, 1983.

22 De Renzi E, Faglioni P. Normative data and screening power of a shortened version of the Token Test. Cortex of a shorten

23 Wechsler D. Wechsler Adult Intelligence Scale-Revised. The New York: Psychological Corporation, 1981.

24 Kiernan $\mathbf{R}$. The neurobehavioral cognitive status examination. San Jose: The Northern California Neurobehavioral Group, 1986.

25 Wechsler D, Stone CP. Wechsler Memory Scale. New York: The Psychological Corporation, 1945.

26 Raven JC. Guide to using the Coloured Progressive Matrices. London: HK Lewis, 1965.

27 Kimura D. Visual Search Test. London, Ontario: Doreen Kimura Consultants, 1985.

28 Rey A. L'examen clinique en psychologie. Paris: Presses Universitaires de France, 1964.

29 Warrington EK. Recognition Memory Test (Faces). Oxford: NFER-Nelson, 1984 .

30 Landis T, Cummings JL, Benson DF. Loss of topographic familiarity: An environmental agnosia. Arch Neurol familiarity: An

31 Nahmias C. The McMaster Positron Emission Tomograph: Design and elevation. Nucl Instrum Methods 1984;1: $113-4$

32 Cogan DG. Visual disturbances with focal progressive dementing disease. Am J Ophthalmol 1985;100:68-72.

33 Damasio A. The anatomical basis of pure alexia. Neurology 1983;33:1573-83.

34 Cummings J, Benson DF. Dementia: A clinical approach. Boston, Butterworths, 1983:35-72.

35 Sevush S. Oral versus semantic reading in Alzheimer's disease. Neurology 1984;34 (Suppl 1):102.

36 Goulding PJ, Northen B, Snowden JS, et al. Progressive aphasia with right-sided extrapyramidal signs: another manifestation of localised cerebral atrophy. $J$ Neurol
Neurosurg Psychiatry 1989;52:12-129.

37 Foster NL, Chase TN, Fedio P, et al. Alzheimer's disease: focal cortical changes shown by positron emission . Nerology 1983;33:961-5.

38 Frackowiak RSJ, Pozzilli C, Legg MJ,, et al. Regional cerebral oxygen supply and utilization in dementia: a clinical and physiological study with oxygen-15 and positron emission tomography. Brain 1981;104:753-78.

39 Friedland RP, Budinger TF, Ganz E, et al. Regional cerebral metabolic alterations in dementia of the Alzheimer's type: positron emission tomography with $[18 \mathrm{~F}]$ flurodeoxyglucose. J Comput Assist Tomogr 1983;7:590-8.

40 Cutler NR, Haxby JV, Duara R, et al. Clinical history, brain metabolism, and neuropsychological function in Alzheimer's disease. Ann Neurol 1985;18:298-309.

41 Haxby JV, Duara R, Grady CL, et al. Relations between neuropsychological and cerebral metabolic asymmetries in early Alzheimer's disease. J Cereb Blood Flow Metab 1985;5:193-200.

42 McGeer PL, Kamo H, Harrop R, et al. Positron emission tomography in patients with clinically diagnosed Alztomography in patients with clinically diagnosed A
heimer's disease. Can Med Assoc J 1986;134:597-607.

43 Kamo H, McGeer P, Harrop R, et al. Positron emission tomography and histopathology in Pick's disease. Neurology 1987;37:439-45.

44 Hof PR, Bouras C, Constantinidis J, Morrison JH. Selective disconnection of specific visual pathways in cases of Alzheimer's disease presenting with Balint's syndrome. $J$ Neuropathol Exp Neurol 1990;49:168-84.

45 Benson DF, Cummings JL, Tsai SY. Angular gyrus syndrome simulating Alzheimer's disease. Arch Neurol 1982;39:616-20.

46 Mandell AM, Alexander MP, Carpenter S. CreutzfeldtJakob disease presenting as isolated aphasia. Neurology 1989;39:55-8.

47 Neumann MA, Cohn R. Long duration Jakob-Creutzfeldt disease. Arch Gerontol Geriatr 1987;6:279-87. 